\title{
Fermentative production of enantiopure (S)-linalool using a metabolically engineered Pantoea ananatis
}

Nobuhisa Nitta * ${ }^{*}$, Yoshinori Tajima, Yoko Yamamoto, Mika Moriya, Akiko Matsudaira, Yasushi Hoshino, Yousuke Nishio and Yoshihiro Usuda

\begin{abstract}
Background: Linalool, an acyclic monoterpene alcohol, is extensively used in the flavor and fragrance industries and exists as two enantiomers, (S)- and (R)-linalool, which have different odors and biological properties. Linalool extraction from natural plant tissues suffers from low product yield. Although linalool can also be chemically synthesized, its enantioselective production is difficult. Microbial production of terpenes has recently emerged as a novel, environmental-friendly alternative. Stereoselective production can also be achieved using this approach via enzymatic reactions. We previously succeeded in producing enantiopure (S)-linalool using a metabolically engineered Pantoea ananatis, a member of the Enterobacteriaceae family of bacteria, via the heterologous mevalonate pathway with the highest linalool titer ever reported from engineered microbes.
\end{abstract}

Results: Here, we genetically modified a previously developed P. ananatis strain expressing the (S)-linalool synthase (AaLINS) from Actinidia arguta to further improve (S)-linalool production. AaLINS was mostly expressed as an insoluble form in P. ananatis; its soluble expression level was increased by $\mathrm{N}$-terminal fusion of a halophilic $\beta$-lactamase from Chromohalobacter sp. 560 with hexahistidine. Furthermore, in combination with elevation of the precursor supply via the mevalonate pathway, the (S)-linalool titer was increased approximately 1.4 -fold $(4.7 \pm 0.3 \mathrm{~g} / \mathrm{L})$ in comparison with the original strain $(3.4 \pm 0.2 \mathrm{~g} / \mathrm{L})$ in test-tube cultivation with an aqueous-organic biphasic fermentation system using isopropyl myristate as the organic solvent for in situ extraction of cytotoxic and semi-volatile (S)-linalool. The most productive strain, IP04S/pBLAAaLINS-ispA*, produced $10.9 \mathrm{~g} / \mathrm{L}$ of (S)-linalool in "dual-phase" fed-batch fermentation, which was divided into a growth-phase and a subsequent production-phase. Thus far, this is the highest reported titer in the production of not only linalool but also all monoterpenes using microbes.

Conclusions: This study demonstrates the potential of our metabolically engineered $P$. ananatis strain as a platform for economically feasible (S)-linalool production and provides insights into the stereoselective production of terpenes with high efficiency. This system is an environmentally friendly and economically valuable (S)-linalool production alternative. Mass production of enantiopure (S)-linalool can also lead to accurate assessment of its biological properties by providing an enantiopure substrate for study.

Keywords: Linalool, Biphasic fermentation, Mevalonate pathway, Solubility tag, Pantoea ananatis

*Correspondence: nobuhisa_nitta@ajinomoto.com Research Institute for Bioscience Products \& Fine Chemicals, Ajinomoto Co., Inc., Kawasaki, Japan

\section{Background}

Terpenes are one of the most abundant classes of natural products with diverse structures and functions (over 50,000 known compounds) and have been widely used as pharmaceuticals, fragrances, and flavors. In plants, 
terpenes are synthesized by terpene synthases (TPSs) from basic five-carbon precursor units, isopentenyl pyrophosphate (IPP) and dimethylallyl pyrophosphate (DMAPP), which are supplied from either the methylerythritol phosphate pathway or mevalonate (MVA) pathway [1]. Microbial terpene production has recently emerged as an ecologically friendly alternative to extraction from natural vegetations (wood and leaf-derived essential oils), which tends to suffer from low product yield [2, 3]. Fermentation products from natural resources are also more economically valuable in the flavor market than their chemically synthesized counterparts because they can be labeled as "natural", aligning with emerging consumer preferences for natural substances $[4,5]$. Additionally, microbial production allows for enantioselective production of terpenes, which is difficult via chemical synthesis, by exploiting the stereoselectivity (enantioselectivity) of enzymatic reactions such as enantiopure production of $(R)$ - $\alpha$-ionone [5] and (-)- $\alpha$-bisabolol [6] in Escherichia coli. However, examples of fermentative terpene production reaching $10 \mathrm{~g} / \mathrm{L}$ titer have been confined to four molecules, viridiflorol, amorpha-4,11-diene [7], $\beta$-farnesene [8] (sesquiterpenes), and isoprene (a hemiterpene) [9], according to our literature search [10].

Linalool, an acyclic monoterpene alcohol, has been widely used as a flavor additive and fragrance ingredient [11]. Linalool is synthesized by linalool synthases from geranyl pyrophosphate (GPP), which is generated by the condensation of IPP and DMAPP by GPP synthase in plants. Linalool exists as two enantiomers, $(S)$ - and $(R)$ linalool, which are differentiated by the chiral properties of the hydroxylated third carbon; the different enantiomers show distinct odors and biological properties [11]. Since commercially available linalool is mainly racemate or $(R)$-linalool, enantiopure $(S)$-linalool is attractive to the flavor and fragrance industries. Enantiopure $(S)$-linalool production has already been reported in Saccharomyces cerevisiae [12] and Yarrowia lipolytica [13] expressing (S)-linalool synthase (AaLINS) from Actinida arguta [14]. We also successfully produced $(S)$-linalool in the cyanobacterium Synechocystis sp. PCC 6803 (Synechocystis) [15] by co-expressing AaLINS and the S80F mutant of farnesyl pyrophosphate synthase (IspA*; from E. coli, functioning as GPP synthase) [16]. However, production levels in these systems range from $240 \mu \mathrm{g} / \mathrm{L}$ to $11.6 \mathrm{mg} / \mathrm{L}$, which cannot meet industrial needs.

Pantoea ananatis, a Gram-negative and yellow-pigmented bacterium, was identified in 1928 and has been mainly studied as a plant pathogen [17]. In the mid1990s, a nonpathogenic P. ananatis strain AJ13355 was isolated by specialists from Ajinomoto Co., Inc. and has been demonstrated to be an excellent host for L-glutamate production because of its capability to grow at an acidic $\mathrm{pH}$ and resist the effects of high concentrations of L-glutamate [18]. The well-developed genetic tools [19, 20] and sequenced complete genome [18] has broadened the attractiveness of $P$. ananatis as a production host for various bio-based materials such as cysteine [21], dicarboxylic acids [22], and isoprene [23]. We constructed a metabolically engineered $P$. ananatis strain named SWITCH-PphoC, which contains heterologous genes of the MVA pathway ( $m v a E$ and $m v a S$ from Enterococcus faecalis; MVA kinase gene from Methanocella paludicola [ $\mathrm{mvk}]$; phosphomevalonate kinase, diphosphomevalonate decarboxylase, and IPP isomerase genes from $S$. cerevisiae), to supply IPP/DMAPP for isoprene production [23]. This strain was designed to direct carbon flux to the MVA pathway only under external inorganic phosphate $\left(\mathrm{P}_{\mathrm{i}}\right)$-starved conditions by using the $\mathrm{P}_{\mathrm{i}}$-starvation-inducible $p h o C$ promoter for driving the expression of the mvaES operon, which encodes the enzymes that catalyze the conversion of acetyl-coenzyme A (CoA) to MVA. Furthermore, enantiopure production of both $(S)$ - and $(R)$-linalool at a titer of greater than $1 \mathrm{~g} / \mathrm{L}$ has been successful with a SWITCH-PphoC strain expressing IspA* and either AaLINS or a $(R)$-linalool synthase from Streptomyces clavuligerus [24], whose genes were optimized based on the codon preference of Synechocystis, under an aqueous-organic biphasic fermentation system in which monoterpene's cytotoxicity and product loss by its airstripping were alleviated [25] using isopropyl myristate (IPM) as an organic solvent [26]. Additionally, the (S)linalool titer was increased by deleting $g c d$ (locus_tag PAJ_3473) encoding a glucose dehydrogenase in the SWITCH-PphoC strain (SWITCH-PphoC $\Delta g c d$ ) [26].

In this study, we chose $(S)$-linalool as the target product and aimed to further improve $(S)$-linalool production through several approaches: (1) by increasing carbon flux to IPP/DMAPP from acetyl-CoA through enhancement of the upper component of the MVA pathway; (2) by increasing intracellular AaLINS activity with $\mathrm{N}$-terminal fusion of a halophilic $\beta$-lactamase (BLA) from Chromohalobacter sp. 560 [27] joined to a hexahistidine $(6 \times \mathrm{His})$; and (3) by adopting an external $\mathrm{P}_{\mathrm{i}}$-dependent so-called "dual-phase" fed-batch fermentation [23], which separates the growth-phase from a subsequent production-phase to increase efficiency [28]. Guided by these approaches, the (S)-linalool titer finally reached $10.9 \mathrm{~g} / \mathrm{L}$ with a $5.1 \%$ [w/w] yield from glucose in the biphasic fermentation system, which demonstrates the potential for industrial-scale enantiopure $(S)$-linalool production using $P$. ananatis. 


\section{Results}

Search for putative rate-limiting reaction to increase (S)-linalool productivity in SWITCH-PphoC $\Delta g c d /$ pAaLINS-ispA* strain

The previously constructed $(S)$-linalool-producing strain (SWITCH-PphoC $\Delta g c d / p A a L I N S$-ispA*) was generated by integrating pACYC177- $\mathrm{P}_{t a c}$-AaLINS-ispA* (pAaLINS-ispA*) [15], a co-expression plasmid for AaLINS and ispA*, into the strain SWITCH-PphoC $\Delta g c d$ [26], which is equipped with genes comprising the whole MVA pathway (Fig. 1). This strain also has a metabolic switch to allow redirection of carbon flux to $(S)$-linalool via the MVA pathway by sensing $\mathrm{P}_{\mathrm{i}}$-starvation with the PhoB/PhoR two-component system [23]. As a result of test-tube cultivation under $\mathrm{P}_{\mathrm{i}}$-starved conditions using a biphasic fermentation system, SWITCH-PphoC $\Delta$ gcd/ pAaLINS-ispA* produced $3.4 \pm 0.2 \mathrm{~g} / \mathrm{L}$ of $(S)$-linalool from $60 \pm 0.0 \mathrm{~g} / \mathrm{L}$ of glucose in $48 \mathrm{~h}$ (Table 1), which was

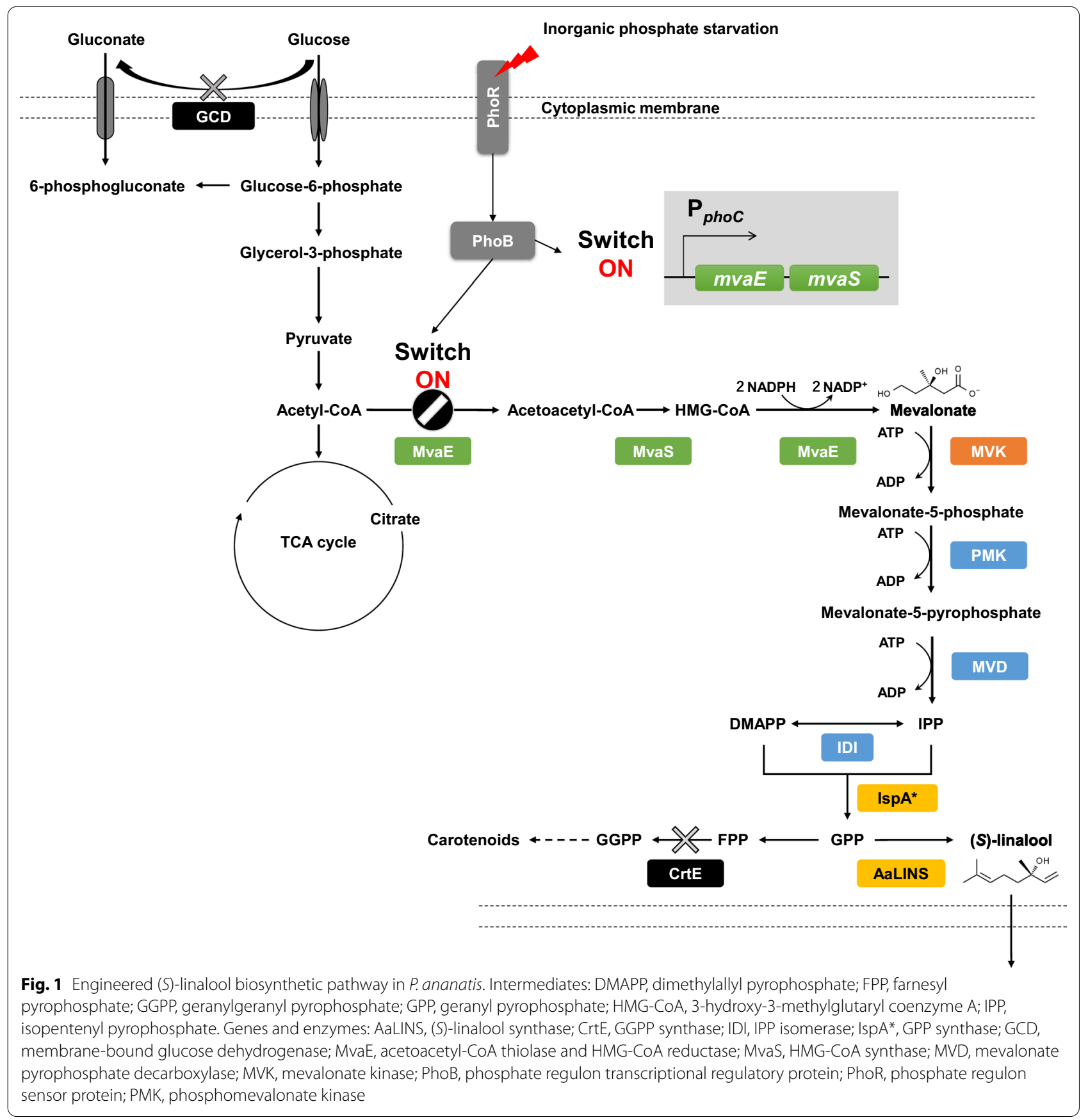


Table 1 (S)-Linalool production in test-tube cultivation

\begin{tabular}{|c|c|c|c|c|}
\hline Host strain & Plasmid & (S)-linalool (g/L) & Consumed glucose $(g / L)^{a}$ & Yield (\%) ${ }^{\mathbf{b}}$ \\
\hline SWITCH-PphoC $\Delta g c d$ & pACYC177 & $N D^{c}$ & $43 \pm 3.3$ & - \\
\hline SWITCH-PphoC $\triangle$ gcd & pAaLINS-ispA* & $3.4 \pm 0.2$ & $60 \pm 0.0$ & $5.6 \pm 0.3$ \\
\hline SWITCH-PphoC $\triangle g c d$ & pBLAAaLINS-ispA* & $3.0 \pm 0.0$ & $60 \pm 0.0$ & $5.0 \pm 0.0$ \\
\hline IP03 & pAaLINS-ispA* & $0.8 \pm 0.0$ & $43 \pm 0.6$ & $1.9 \pm 0.0$ \\
\hline IP03 & pBLAAaLINS-ispA* & $4.0 \pm 0.2$ & $60 \pm 0.0$ & $6.6 \pm 0.4$ \\
\hline IP04 & pACYC177 & ND & $38 \pm 1.7$ & - \\
\hline IP04 & pAaLINS-ispA* & $1.0 \pm 0.0$ & $36 \pm 0.6$ & $2.8 \pm 0.1$ \\
\hline IP04 & pBLAAaLINS-ispA* & $4.7 \pm 0.3$ & $60 \pm 0.0$ & $7.9 \pm 0.2$ \\
\hline
\end{tabular}

All strains were cultivated for $48 \mathrm{~h}$ under biphasic fermentation using isopropyl myristate. Data are expressed as the mean \pm SD of at least three biological replicates

a Glucose and (S)-linalool concentrations are represented by dividing the total amounts by the volume of aqueous culture

b Yield was calculated as grams of product per grams of consumed glucose and is expressed as a percentage. Carbon sources contained in $2 \mathrm{~g} / \mathrm{L}$ of Bacto yeast extract was not considered in this calculation

c ND, Not detected

greater than the reported linalool titers from yeasts [12, $13,29,30]$ and bacteria [15, 31]. As our previous study showed that additional integration of an mvaES operon expression-cassette led to higher productivity in an isoprene-producing $P$. ananatis strain [32], the strain IP03 was constructed by integrating one mvaES operon expression-cassette into the genome of SWITCH-PphoC $\Delta g c d$. The strain IP04 was also constructed from IP03 by integrating one $m v k$ expression-cassette to increase carbon flux to IPP/DMAPP. However, strains IP03 and IP04 harboring pAaLINS-ispA* (IP03/pAaLINS-ispA* and IP04/pAaLINS-ispA*) showed lower sugar consumption and (S)-linalool productivity than SWITCH-PphoC

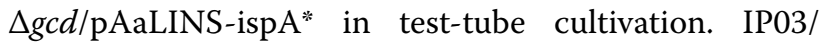
pAaLINS-ispA* and IP04/pAaLINS-ispA* were unable to completely consume the initial glucose in $48 \mathrm{~h}(43 \pm 0.6$ and $36 \pm 0.6 \mathrm{~g} / \mathrm{L})$, unlike SWITCH-PphoC $\Delta g c d / \mathrm{pAaL}-$ INS-ispA*, and consequently produced only $0.8 \pm 0.0$ and $1.0 \pm 0.0 \mathrm{~g} / \mathrm{L}$ of $(S)$-linalool, respectively (Table 1 ). This result indicates that their lower sugar consumptions may result from intracellular accumulation of cytotoxic intermediates such as IPP and DMAPP [7, 33]. This assumption was supported by the observation that SWITCH-PphoC $\Delta g c d$ and IP04 harboring the empty vector (pACYC177), which are likely to accumulate IPP/ DMAPP intracellularly because of the lack of linalool synthase, were unable to completely consume all initial glucose in $48 \mathrm{~h}(43 \pm 3.3$ and $38 \pm 1.7 \mathrm{~g} / \mathrm{L}$, Table 1$)$. These results indicate that a rate-limiting step in $(S)$-linalool production exists among the reactions from IPP/DMAPP to $(S)$-linalool.

\section{Approaches to improve intracellular AaLINS activity}

Since the lower sugar consumption in IP04/pAaLINS-ispA* was thought to be attributed to isoprenoid precursor toxicity, which has been reported to be relieved by enhanced TPS activity [34], AaLINS activity was suspected of being a potential bottleneck in $(S)$ linalool production. Several TPSs have been identified as primary bottlenecks in terpene biosynthesis because of their poor in vivo properties [35, 36]. In the experiments described above, AaLINS and ispA*, which were codon-optimized for Synechocystis [15], were used even in $P$. ananatis; however, the codon usages of heterologous eukaryotic genes are commonly optimized for the prokaryotic host $[6,7,31,36]$ in order to improve their translation rate or efficiency. Therefore, the plasmid pAaLINS_pa-ispA*_pa expressing AaLINS_pa and isp $A^{*}$. $p a$ which were optimized to match the codonpreference of $P$. ananatis was constructed to increase AaLINS production or activity (Additional file 1: Figure S1 and S2). To confirm whether the expression level of AaLINS was increased by synonymous substitution of codons of AaLINS and ispA*, sodium dodecyl sulfate-polyacrylamide gel electrophoresis (SDS-PAGE) was conducted with samples of both SWITCH-PphoC

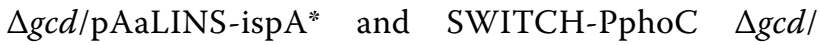
pAaLINS_pa-ispA*_pa. As a result, a putative band of AaLINS (molecular mass: $63 \mathrm{kDa}$ ) was observed in the crude homogenate containing soluble and insoluble proteins, whereas the band of AaLINS_pa was not visible even in the crude homogenate (Additional file 1: Figure S3). Contrary to our expectation, these data revealed that the total expression level of AaLINS_pa was lower than that of AaLINS, even after the codon-optimization for $P$. ananatis. Consistently, strain SWITCH-PphoC $\Delta g c d /$ pAaLINS_pa-ispA*_pa produced only $13 \pm 1.2 \mathrm{mg} / \mathrm{L}$ of $(S)$-linalool in test-tube cultivation (Additional file 1: Table S1), indicating that 
codon-optimization of AaLINS and ispA* for Synechocystis unexpectedly led to higher AaLINS expression and $(S)$-linalool titers.

Meanwhile, SDS-PAGE revealed that AaLINS was mostly expressed as insoluble forms in P. ananatis; the band of AaLINS was mainly detected in the insoluble fraction (Additional file 1: Figure S3). Specific solubility-tag fusion to the N-terminus of the TPS improves its solubility in E. coli, as was found with fusion of the small ubiquitin-like modifier (SUMO) to the (+)-zizaene synthase from Chrysopogon zizanioides [37], and of the maltose binding protein (MBP) to the valencene synthase from Callitropsis nootkatensis [38]. Therefore, the N-terminal solubility-tag fusion approach was adopted for AaLINS to increase its soluble expression level. To identify an effective fusion partner protein for AaLINS, six solubility-tags joined to a $6 \times$ His (AFV1-99 protein from Acidianus filamentous virus 1, BLA, MBP, FKBP-type peptidyl-prolyl cis-trans isomerase, SUMO, and an E. coli elongation factor) were evaluated with the $P$. ananatis $\mathrm{SC17(0)}$ strain [19] using ready-to-use pSol vectors [39]. Each of the six constructed strains expressed AaLINS fused with one of six solubility-tags under control of a rhamnoseinducible promoter. Control strains capable of expressing untagged AaLINS or a $6 \times$ His-tagged AaLINS were also constructed (SC17(0)/pSol-AaLINS and SC17(0)/ pSol-HisAaLINS). The results of SDS-PAGE reconfirmed that AaLINS was mostly expressed as insoluble forms in P. ananatis. Bands of $6 \times$ His-tagged AaLINS and untagged AaLINS were not visible in their soluble protein fractions, whereas they were observed in the crude homogenates (Fig. 2). A faint band appeared at approximately $60 \mathrm{kDa}$ in the untagged control lane in the gel stained with anti-polyhistidine label, which was non-specific (Fig. 2c). In contrast, a band of $6 \times$ His-BLA-fused AaLINS (molecular mass: $105 \mathrm{kDa}$ ) was observed in the soluble protein fraction by both Coomassie Brilliant Blue (CBB) staining and fluorescence staining of His-tagged proteins (Fig. 2b, d). The difference in the migration of $6 \times$ His-BLA-fused AaLINS between the crude homogenate and soluble fraction may have occurred due to overloading of AaLINS derived from the insoluble fraction. Fusion of other evaluated solubility-tags did not improve the solubility from baseline or showed a lower degree of improvement than the $6 \times$ His-BLA-fusion (Fig. 2). Aside from solubility, all seven AaLINS variants fused with each solubility-tag appeared to show higher total (insoluble and soluble forms) expression level than untagged AaLINS (Fig. 2a, b). These results indicate that the $\mathrm{N}$-terminal $6 \times$ His-tag fusion itself influences the total AaLINS expression level and demonstrate that fusing
$6 \times$ His-BLA to AaLINS is the most promising means of increasing its intracellular expression level, solubility, and activity.

\section{Biotransformation assay with $6 \times$ His-BLA-fused AaLINS}

An in vitro biotransformation assay was conducted to confirm whether $6 \times$ His-BLA-fused AaLINS still retained the capability of converting GPP to (S)-linalool, and whether intracellular AaLINS activity could be increased by $6 \times$ His-BLA-fusion. The assay consisted of adding crude homogenate or soluble protein fraction of SC17(0)/pSol-AaLINS, SC17(0)/pSol-HisAaLINS, and $\mathrm{SC} 17(0) / \mathrm{pSol}-\mathrm{BLAAaLINS}$ to the reaction mixture containing the substrate (GPP) and cofactor $\left(\mathrm{Mg}^{2+}\right)$, respectively. After a 26 -h reaction at $30^{\circ} \mathrm{C}, 273 \pm 23,241 \pm 3$, and $550 \pm 45 \mu \mathrm{g} / \mathrm{L}$ of $(S)$-linalool was detected in the reaction buffer containing the soluble protein fraction of SC17(0)/pSol-AaLINS, SC17(0)/pSol-HisAaLINS, and SC17(0)/pSol-BLAAaLINS, respectively (Fig. 3). When the crude homogenates were used for the assay, $339 \pm 15$, $514 \pm 26$, and $669 \pm 80 \mu \mathrm{g} / \mathrm{L}$ of $(S)$-linalool was detected in the reaction buffer containing samples of SC17(0)/ pSol-AaLINS, SC17(0)/pSol-HisAaLINS, and SC17(0)/ pSol-BLAAaLINS, respectively (Fig. 3). This result shows that fusing only $6 \times$ His-tag to AaLINS increased its total activity despite nearly no solubility enhancement compared to untagged AaLINS (Fig. 2), which was supported by the result that the $(S)$-linalool titer of strain SWITCHPphoC $\Delta g c d$ expressing IspA*_pa and $6 \times$ His-tagged AaLINS_pa (306 $\pm 49 \mathrm{mg} / \mathrm{L})$ was approximately 30 times higher than that of SWITCH-PphoC $\Delta g c d /$ pAaLINS_paispA*_pa (Additional file 1: Table S1). These data reveal that even with the $6 \times$ His-BLA-moiety attached, the $(S)$ linalool producing capability was maintained, and that $\mathrm{N}$-terminal fusion of $6 \times \mathrm{His}-\mathrm{BLA}$ increased the total intracellular AaLINS activity.

\section{Collective impact of $6 \times$ His-BLA-fusion to AaLINS and enhancement of the MVA pathway on (S)-linalool production}

To evaluate the impact of $6 \times$ His-BLA-fusion to AaLINS on (S)-linalool production, strains SWITCH-PphoC $\Delta g c d$, IP03, and IP04 harboring pBLAAaLINS-ispA*, a plasmid for over-expressing IspA* and $6 \times$ His-BLA-fused AaLINS, were cultured in test tubes. IP03/pBLAAaLINS-ispA* and IP04/pBLAAaLINS-ispA* produced $4.0 \pm 0.2 \mathrm{~g} / \mathrm{L}$ of $(S)$-linalool with a $6.6 \pm 0.4 \%$ yield and $4.7 \pm 0.3 \mathrm{~g} / \mathrm{L}$ of $(S)$-linalool with a $7.9 \pm 0.2 \%$ yield, respectively (Table 1). Both IP03/pBLAAaLINS-ispA* and IP04/ pBLAAaLINS-ispA* completely consumed the initial glucose, unlike IP03/pAaLINS-ispA* and IP04/pAaLINSispA* These data indicate that the bottleneck of $(S)$-linalool production in IP04/pAaLINS-ispA*, which expressed 


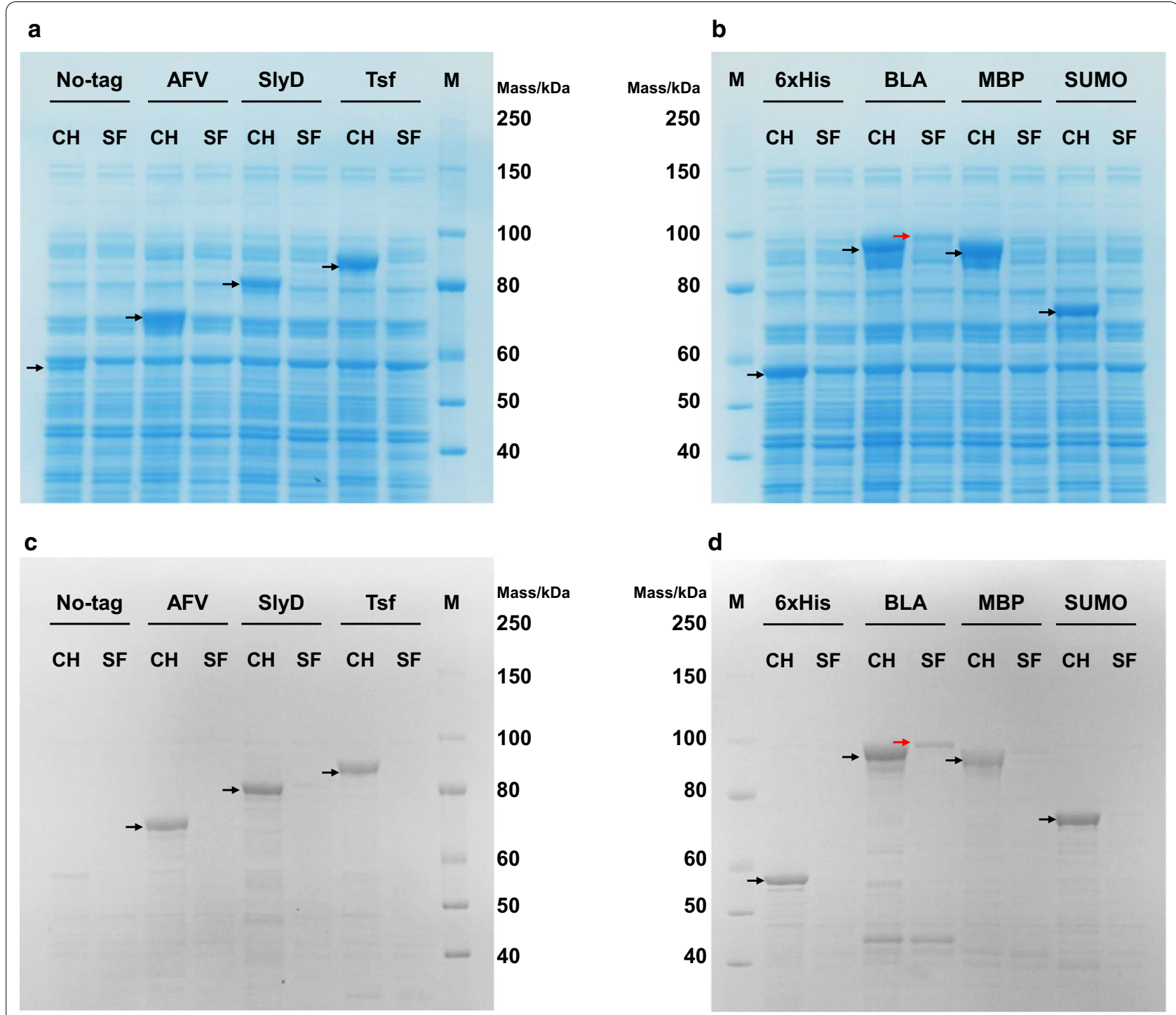

Fig. 2 SDS-PAGE gels illustrating total and soluble expression levels of solubility-tag fused AaLINS variants. a, b Gels stained with Coomassie Brilliant Blue; $\mathbf{c}, \mathbf{d}$ Gels stained with an anti-polyhistidine label (a fluorescent dye conjugated to nickel-nitrilotriacetic acid complex). CH, SF, and M denote crude homogenate, soluble fraction, and protein standard, respectively. Samples were prepared from SC17(0) harboring each pSol plasmid grown in LB medium containing rhamnose. Each applied sample contained $10 \mu \mathrm{g}$ of soluble proteins. Arrow shows each AaLINS variant. AFV, AFV1-99 protein from Acidianus filamentous virus 1; BLA, halophilic $\beta$-lactamase from Chromohalobacter sp. 560; $6 \times$ His, hexahistidine; MBP, maltose binding protein; SlyD, FKBP-type peptidyl-prolyl cis-trans isomerase; SUMO, small ubiquitin-like modifier; Tsf, E. coli elongation factor

untagged AaLINS, was intracellular AaLINS activity. In contrast, SWITCH-PphoC $\Delta g c d /$ pBLAAaLINS-ispA* produced only $3.0 \pm 0.0 \mathrm{~g} / \mathrm{L}$ of $(\mathrm{S})$-linalool, which was almost the same as that produced by SWITCH-PphoC $\Delta g c d / \mathrm{pAaLINS}$-ispA* $(3.4 \pm 0.2 \mathrm{~g} / \mathrm{L})$ (Table 1). Therefore, the putative bottleneck for $(S)$-linalool production in SWITCH-PphoC $\Delta g c d /$ pBLAAaLINS-ispA* was the supply of IPP/DMAPP or GPP, and this bottleneck was eliminated by the additional integration of the mvaES operon and $m v k$ expression cassette in a step-by-step manner. As a result of the collective effects of both the higher intracellular AaLINS activity imparted by fusion to $6 \times$ HisBLA and higher GPP supply by enhancement of the MVA pathway, the $(S)$-linalool titer of IP04/pBLAAaLINSispA* was approximately 1.4-fold greater than that of SWITCH-PphoC $\Delta g c d /$ pAaLINS-ispA*.

In addition, to confirm whether the linalool synthesized from GPP by $6 \times$ His-BLA-fused AaLINS was still exclusively $(S)$-enantiomer, the culture sample of SWITCHPphoC $\Delta g c d /$ pBLAAaLINS-ispA* was analyzed by gas 


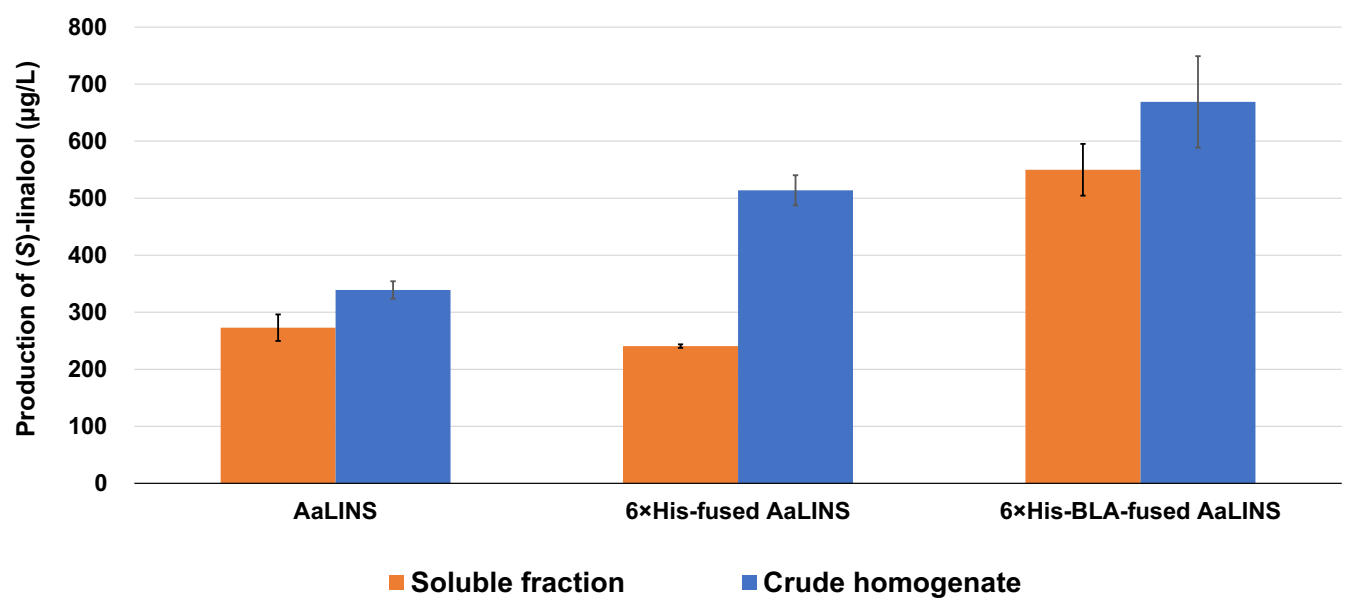

Fig. 3 In vitro biotransformation assay with samples prepared from SC17(0)/pSol-AaLINS, SC17(0)/pSol-HisAaLINS, and SC17(0)/pSol-BLAAaLINS The strains were grown in LB medium containing rhamnose. Each reaction mixture contained $300 \mathrm{mg} / \mathrm{L}$ of soluble proteins. Data represent the average of three biological replicates, and error bars represent the standard deviation

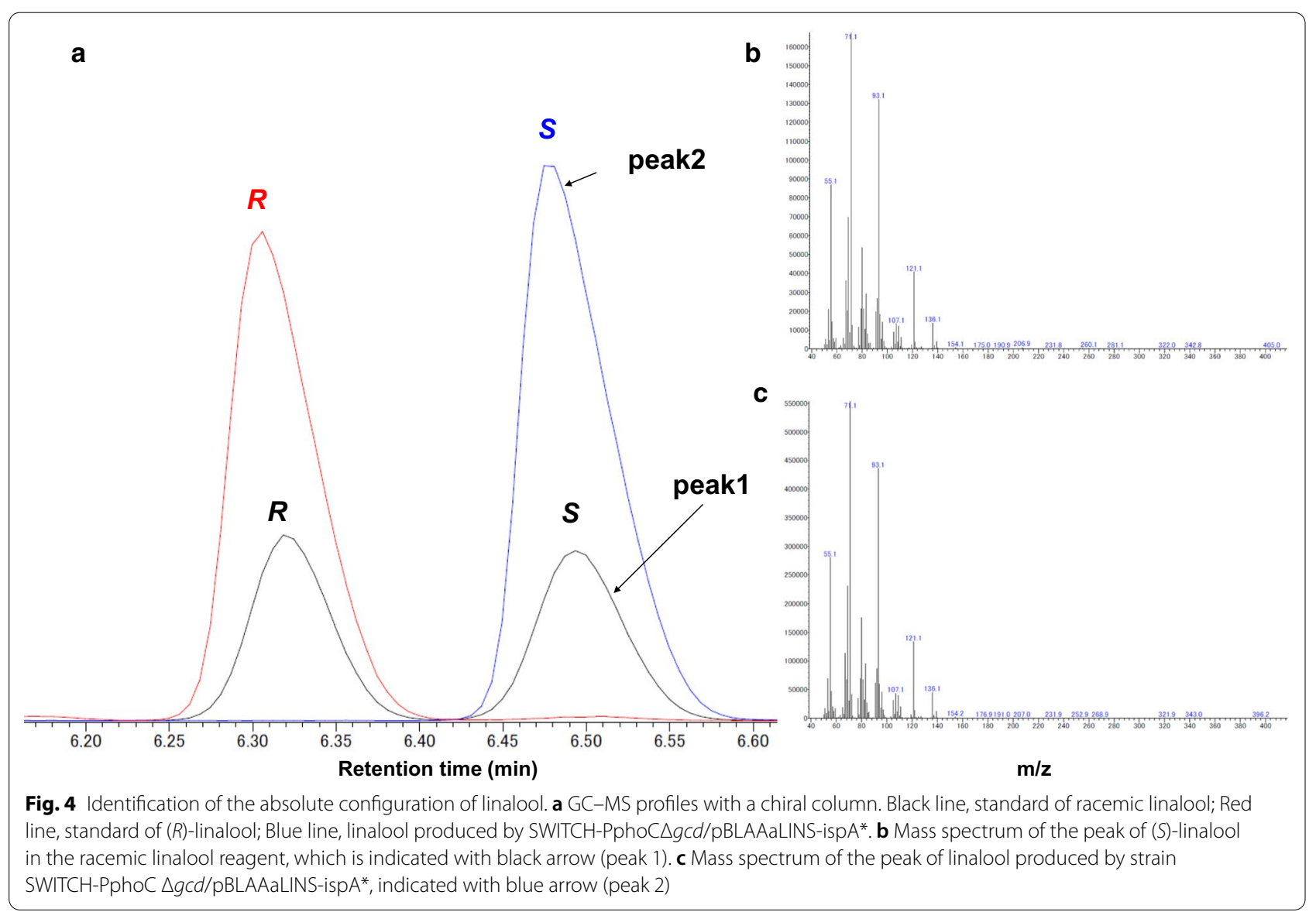

chromatography mass spectrometry (GC-MS) with a chiral column. Only one enantiomer (retention time: $6.5 \mathrm{~min}$ ) was detected in the sample (Fig. 4a); its peak corresponded to the $(S)$-enantiomer peak of racemic linalool. Furthermore, the fragment ion mass spectrum of this product matched the spectral data of the linalool 
standard (Fig. 4b, c). These data reveal that $6 \times$ His-BLAfusion did not affect the enantioselectivity of AaLINS.

\section{Fed-batch fermentation with IP04/ pBLAAaLINS-ispA* strain}

To investigate the $(S)$-linalool-producing ability of IP04S/ pBLAAaLINS-ispA*, a fed-batch fermentation, which is relevant to industrial processes, was conducted in a 1-L scale fermenter; SWITCH-PphoC $\Delta g c d /$ pAaLINSispA* was also cultured as a control strain. One prominent strategy for high terpene production is to divide fermentation into a growth-phase and a subsequent production-phase (dual-phase fermentation), as this method can bypass the allocation of substrate between cell-growth and the target product and alleviate the effects of the accumulation of cytotoxic intermediates from the MVA pathway during the growth phase [28].
An external $\mathrm{P}_{\mathrm{i}}$-dependent dual-phase fed-batch fermentation process was previously established for isoprene production using the SWITCH-PphoC strain [23]. The $\mathrm{P}_{\mathrm{i}}$-starvation-inducible metabolic switch enables cells to grow efficiently under the $\mathrm{P}_{\mathrm{i}}$-saturated phase and efficiently produce $(S)$-linalool under the subsequent $\mathrm{P}_{\mathrm{i}}$-starved phase. Thus, a $\mathrm{P}_{\mathrm{i}}$-starved fed-batch fermentation $\left(1.8 \mathrm{~g} / \mathrm{L}\right.$ of $\left.\mathrm{KH}_{2} \mathrm{PO}_{4}\right)$ was conducted using the biphasic fermentation system. The culture temperature was optimized from the previous study [23] in which the culture temperature was set at $33^{\circ} \mathrm{C}$. The results are summarized in Fig. 5. As the optical density at $600 \mathrm{~nm}\left(\mathrm{OD}_{600}\right)$ could not represent the biomass concentration accurately owing to oil-in-water emulsion formation in biphasic fermentation [40], the profile of the $\mathrm{CO}_{2}$ concentration in the exhausted gas $\left(\mathrm{ExCO}_{2}\right)$ was exploited as an index of total cell activity in the fermenter. The patterns of $\mathrm{ExCO}_{2}$ showed almost no difference between the two strains for

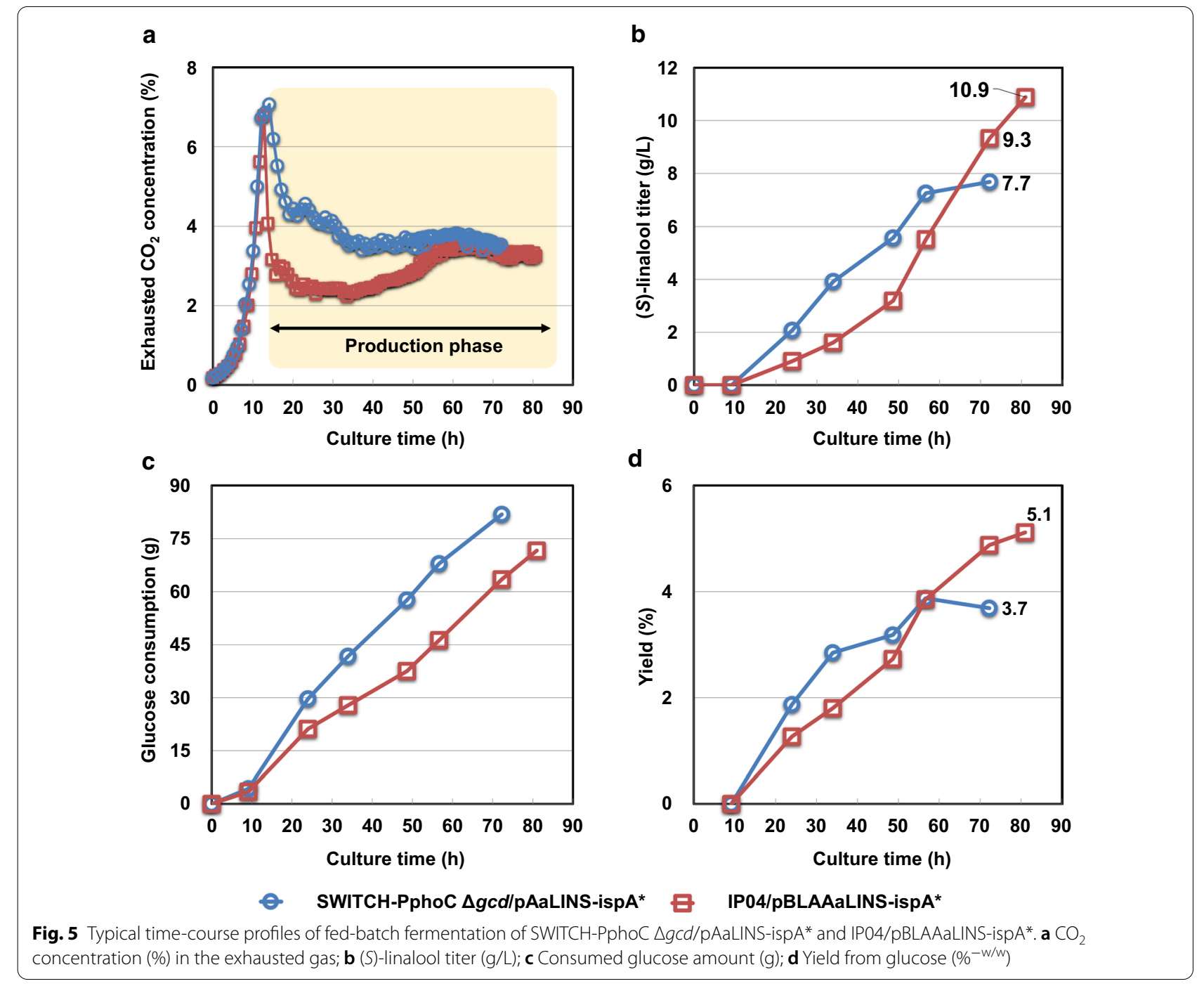


up to $13 \mathrm{~h}$ of cultivation (Fig. 5a), which indicates that both strains grew with the same efficiency regardless of their genotypic differences. This result demonstrates that our $\mathrm{P}_{\mathrm{i}}$-dependent dual-phase process contributed to overcoming both the competition for acetyl-CoA between cell-growth and (S)-linalool and intracellular accumulation of cytotoxic compounds in the growth phase. This feature of dual-phase fermentation also enables estimation of the approximate cell density when transiting to $(S)$-linalool production phase $\left(\mathrm{P}_{\mathrm{i}}\right.$-starved phase), despite the difficulty of monitoring the actual cell density with $\mathrm{OD}_{600}$ values in biphasic fermentation. The growth profile during the $\mathrm{P}_{\mathrm{i}}$-saturated phase should be nearly the same regardless of the existence of IPM and genotypic differences. When the strain SWITCH-PphoC $\Delta g c d / p$ AaLINS-ispA* was cultured $\left(1.8 \mathrm{~g} / \mathrm{L}\right.$ of $\left.\mathrm{KH}_{2} \mathrm{PO}_{4}\right)$ without IPM, its $\mathrm{OD}_{600}$ value at $13 \mathrm{~h}$ was 33 . The $\mathrm{ExCO}_{2}$ of both strains declined at $13 \mathrm{~h}$ of cultivation (Fig. 5a), demonstrating that external $\mathrm{P}_{\mathrm{i}}$-starvation started at this time. After entering the $\mathrm{P}_{\mathrm{i}}$-starved phase, the $\mathrm{ExCO}_{2}$ profile of IP04/pBLAAaLINS-ispA* was lower than that of SWITCH-PphoC $\Delta g c d /$ pAaLINS-ispA* (Fig. 5a), indicating that IP04/pBLAAaLINS-ispA* redirected higher carbon flux from acetyl-CoA to the MVA pathway from the tricarboxylic acid (TCA) cycle, which generates $\mathrm{CO}_{2}$ and NADH for cell respiration, as compared to SWITCHPphoC $\Delta g c d /$ pAaLINS-ispA*. SWITCH-PphoC $\Delta g c d /$ pAaLINS-ispA* accumulated higher levels of $(S)$-linalool than IP04/pBLAAaLINS-ispA* until approximately $60 \mathrm{~h}$ of cultivation (Fig. 5b). However, at $72 \mathrm{~h}$ of cultivation, despite less sugar consumption (63.5 g, Fig. 5c), IP04/ pBLAAaLINS-ispA* produced larger amounts of $(S)$ linalool $(9.3 \mathrm{~g} / \mathrm{L})$ than SWITCH-PphoC $\Delta g c d /$ pAaLINSispA*, which produced $7.7 \mathrm{~g} / \mathrm{L}$ of $(S)$-linalool from $81.4 \mathrm{~g}$ of glucose (3.7\% yield). A similar fermentation profile was observed in the other fed-batch fermentation (Additional file 1: Figure S4), though the culture temperature and initial $\mathrm{KH}_{2} \mathrm{PO}_{4}$ concentration $(1.6 \mathrm{~g} / \mathrm{L})$ were different. Since the $(S)$-linalool titer of IP04/pBLAAaLINS-ispA* was still linearly increasing at $72 \mathrm{~h}$ of cultivation unlike SWITCH-PphoC $\Delta g c d /$ pAaLINS-ispA* (Fig. 5b), the culture time of IP04/pBLAAaLINS-ispA* was elongated to $81 \mathrm{~h}$. As a result, IP04/pBLAAaLINS-ispA* produced a total of $10.9 \mathrm{~g} / \mathrm{L}$ (final concentration) of (S)-linalool from $72.4 \mathrm{~g}$ of glucose $(5.1 \%$ yield), whereas it accumulated $7.2 \mathrm{~g} / \mathrm{L}$ of MVA in the aqueous culture medium as a main by-product.

\section{Discussion}

Although advancements in the field of metabolic engineering have improved the production level of terpenes, linalool production has been confined to the $\mathrm{mg} / \mathrm{L}$-scale $[12,13,15,29-31]$. However, our metabolically engineered $P$. ananatis strain IP04/ pBLAAaLINS-ispA* produced enantiopure $(S)$-linalool with a $10.9 \mathrm{~g} / \mathrm{L}$ titer under $\mathrm{P}_{\mathrm{i}}$-dependent dual-phase fedbatch fermentation. This is the highest reported titer for microbial production of not only $(S)$-linalool but also all monoterpenes [10].

In this study, the use of AaLINS (codon-optimized for Synechocystis) unexpectedly led to higher AaLINS expression compared to the use of AaLINS_pa (codonoptimized for $P$. ananatis). When we previously evaluated 8 homologs of AaLINS, the codons of which were optimized for $P$. ananatis based on the OptimumGene algorithm [41], in SWITCH-PphoC $\Delta g c d$, the linalool titers were less than $120 \mathrm{mg} / \mathrm{L}$, although SWITCHPphoC $\Delta g c d /$ pAaLINS-ispA* produced $1.6 \mathrm{~g} / \mathrm{L}$ of $(S)$-linalool [26]. Further studies of the codon-optimization of linalool synthases are required. We also found that AaLINS was mainly expressed as insoluble form in $P$. ananatis. To improve AaLINS solubility, a solubility-tag fusion approach was applied to AaLINS. This approach is one of the commonly used methods for increasing the solubility of "difficult-to-express" heterologous proteins in bacterial cells. As a result of screening commonly used solubility-tags, $6 \times$ His-BLA was identified as a suitable one for AaLINS to increase its soluble production level; however, AaLINS aggregation could not be completely avoided by the $\mathrm{N}$-terminal $6 \times$ His-BLA-fusion as observed in SDSPAGE analysis, which demonstrates the positive effect of $6 \times$ His-BLA-fusion on solubility improvement is limited. Additionally, the mechanism of action underlying differences in solubility-tag efficacy has not been investigated. Furthermore, it has been revealed that $6 \times$ His-fusion may increase the expression level and activity, as seen in a previous study of a hyaluronidase production in a methylotrophic yeast [42].

Unlike SWITCH-PphoC $\Delta g c d / \mathrm{pAaLINS}$-ispA*, IP04/ pAaLINS-ispA* was unable to completely consume the initial glucose in $48 \mathrm{~h}$ as well as IP04/pACYC177 in testtube cultivation. IP04/pAaLINS-ispA* likely stopped consuming glucose after the start of $P_{i}$ starvation because of over-accumulation of cytotoxic IPP/DMAPP, which led to a lower $(S)$-linalool titer. Compared to SWITCHPphoC $\Delta g c d$, IP04 is more likely to accumulate these cytotoxic intermediates intracellularly because of enhanced carbon flux to the MVA pathway when AaLINS activity was not high enough to avoid their excess accumulation. This issue was attenuated by increased intracellular AaLINS activity via $6 \times$ His-BLA-fusion. IP04/pBLAAaLINS-ispA* completely consumed the initial glucose and showed higher productivity compared to SWITCH-PphoC $\Delta g c d /$ pBLAAaLINS-ispA*.

Our $\mathrm{P}_{\mathrm{i}}$-exploiting dual-phase fed-batch fermentation process has advantages for industrial-scale production, 
including simple operation to transit cells to the production phase, no requirement for exogenous inducers, and restricted respiratory activity, which is required for aerobic fermentation at industrial scale in order to fulfill technical constraints such as oxygen and heat transfer. Furthermore, we can aim to achieve the theoretical $(S)$ linalool yield from glucose in the production $\left(\mathrm{P}_{\mathrm{i}}\right.$-starved) phase. This is because ATP production and consumption can be stoichiometrically balanced from glucose to (S)-linalool via standard Embden-Meyerhof-Parnas (EMP) glycolysis and the MVA pathway [9, 43]. Four moles of NADPH, which are required to yield one mole of $(S)$-linalool from 6 acetyl-CoA via the MVA pathway, can be supplied via the EMP glycolysis by providing 12 $\mathrm{NADH}$ to yield 6 acetyl-CoA from 3 glucose as long as NAD $(\mathrm{P})$ transhydrogenase (locus tag PAJ_1324 and 1325) is functional $[9,43]$. To realize this, we aim to improve our $\mathrm{P}_{\mathrm{i}}$-dependent metabolic switch to allow for dynamic metabolic control by developing conditional metabolic on/off systems [44] to shut off carbon flux to competing pathways such as TCA cycle and oxidative pentose-phosphate pathway, which is estimated to be upregulated by $\mathrm{P}_{\mathrm{i}}$-starvation [45].

The yield (5.6\%) in fed-batch fermentation was lower than that in the test-tube cultivation $(7.9 \pm 0.2 \%)$. However, the yield could be increased by elongating cultivation time (production-phase), as the cumulative yield continued to increase along with the culture time at the termination of production (Fig. 5d). Our next target is to further increase the $(S)$-linalool yield and titer; however, the upper limit of the titer is closely related to the properties and amount of in situ extraction organic solvent (IPM). Higher production of (S)-linalool by the P. ananatis strain leads to a higher $(S)$-linalool titer in the aqueous medium, according to the $(S)$-linalool distribution coefficient for IPM. Once more than $1 \mathrm{~g} / \mathrm{L}$ of cytotoxic $(S)$ linalool accumulated in the aqueous phase, the growth and metabolic activity of $P$. ananatis were significantly reduced (Additional file 1: Figure S5), as reported for other Gram-negative bacteria [11, 46], and (S)-linalool production would be hampered. IPM has been used as an organic solvent in our studies $[15,26]$ because of its high biocompatibility with microbes and high distribution coefficient of monoterpenes [25]. However, IPM is not an economically viable solvent; thus, not only increasing the titer but also enhancing the resistance to monoterpene toxicity of $P$. ananatis $[46,47]$ to decrease the amount of IPM are necessary to reduce the production cost for industrial production.

IP04/pBLAAaLINS-ispA* accumulated 7.2 g/L of MVA into the medium at the end of fed-batch fermentation, which suggests that a pathway downstream of $(S)$-linalool biosynthesis, particularly AaLINS activity, may still be a potent bottleneck in this strain. Therefore, additional means may be required to increase intracellular $(S)$-linalool synthase activity. Lowering the culture temperature or co-expression of chaperones, which is known to improve heterologous protein solubility [48], should be considered; using protein engineering to screen mutant variants of AaLINS with improved performance is also an option [35, 36]. Another prominent option is using other linalool synthases that are known to produce only the $(S)$-enantiomer such as those from Cinnamomum osmophloeum [49] or Malus domestica [50] if their kinetic parameters and solubilities in bacteria are superior to those of AaLINS. Additionally, our platform strain and fermentation process can theoretically synthesize a multitude of different monoterpenes with almost the same productivity as $(S)$-linalool by changing only AaLINS to other mono-TPS, although it would depend on the solubility/stability and kinetic parameters of mono-TPS.

\section{Conclusions}

We achieved a $10.9 \mathrm{~g} / \mathrm{L}$ titer of $(S)$-linalool on the basis of SWITCH-PphoC $\Delta g c d /$ pAaLINS-ispA* via three main approaches: (1) improving intracellular activity of AaLINS, (2) increasing the precursor (GPP) supply, and (3) applying dual-phase fed-batch fermentation. Our results demonstrate that fermentative enantiopure "natural" $(S)$ linalool production with a metabolically engineered $P$. ananatis strain is a promising system that is environmentally-friendly and can be readily industrialized, although additional studies are needed to improve the economic viability of this process. Mass production of enantiopure $(S)$-linalool may contribute to accurate assessment of its biological properties, as most studies have been performed with $(R)$-linalool or linalool racemate [11].

\section{Methods}

\section{Bacterial strains, plasmids, and growth conditions}

The primary bacterial strains and plasmids used in this study are listed in Table 2. Other strains and plasmids used as materials for strain construction are listed in Additional file 1: Table S2. The primers used in this study are listed in Additional file 1: Table S3. E. coli strain JM109 (Takara Bio, Otsu, Japan) was primarily used for plasmid cloning and propagation. The DNA fragment was cloned into a linearized vector with an In-Fusion ${ }^{\circledR}$ HD cloning kit (Takara Bio). The plasmid was transformed into $P$. ananatis as previously reported [19]. Antibiotics were used to maintain plasmids or screen antibiotic-resistant transformants with the following concentrations: chloramphenicol $(\mathrm{Cm}: 60 \mathrm{mg} / \mathrm{L})$, kanamycin (Km: $50 \mathrm{mg} / \mathrm{L})$, and tetracycline (Tet: $10 \mathrm{mg} / \mathrm{L})$. 
Table 2 Bacterial strains and plasmids used in this study

\begin{tabular}{|c|c|c|c|}
\hline Strain or plasmid & Description & $\begin{array}{l}\text { Antibiotic } \\
\text { resistance }^{\text {a }}\end{array}$ & Source or reference \\
\hline \multicolumn{4}{|l|}{ Pantoea ananatis } \\
\hline $\mathrm{SC} 17(0)$ & $\lambda$ Red resistant strain & - & [19] \\
\hline SWITCH-PphoC $\triangle g c d$ & $\mathrm{SC} 17(0) \Delta a m p C: \because \mathrm{P}_{\text {tac }}-\mathrm{KD}$ yl $\triangle a m p H:: \mathrm{P}_{\text {phoc }}-m v a E S \Delta c r t E X Y I B-c r t Z:: \mathrm{P}_{\text {tac }}-m v k \Delta g c d$ & - & [26] \\
\hline IP03 & SWITCH-PphoC $\triangle g c d \Delta L-I d h:: P_{p h o c}-m v a E S$ & - & This study \\
\hline IP04 & IP03 $\triangle a d h E:: P_{t a c}-\varphi 10-m v k$ & - & This study \\
\hline \multicolumn{4}{|l|}{ Plasmid } \\
\hline pSol-AaLINS & $\begin{array}{l}\text { pSol plasmid for expression of AaLINS under the control of a rhamnose-inducible pro- } \\
\text { moter }\end{array}$ & $\mathrm{Km}$ & This study \\
\hline pSol-HisAaLINS & pSol plasmid for expression of hexahistidine-tagged AaLINS & $\mathrm{Km}$ & This study \\
\hline pSol-BLAAaLINS & $\begin{array}{l}\text { pSol plasmid for expression of AaLINS fused with } \beta \text {-lactamase from Chromohalobacter sp. } \\
560 \text { joined to hexahistidine }\end{array}$ & $\mathrm{Km}$ & This study \\
\hline $\begin{array}{l}\text { PACYC177-P } \text { tac }^{-} \\
\text {AaLINS-ispA* } \\
(\text { pAaLINS-ispA*) }\end{array}$ & pACYC177 derivative for expression of AaLINS and ispA* under the control of tac promoter & $\mathrm{Km}$ & {$[15]$} \\
\hline pBLAAaLINS-ispA* & $\begin{array}{l}\text { pACYC177 derivative for expression of the gene of AaLINS fused with } \beta \text {-lactamase from } \\
\text { Chromohalobacter sp. } 560 \text { joined to hexahistidine and ispA* under the control of tac } \\
\text { promoter }\end{array}$ & $\mathrm{Km}$ & This study \\
\hline
\end{tabular}

Km kanamycin

\section{Construction of plasmids for expressing solubility-tag fused AaLINS}

An Expresso Solubility and Expression Screening System (Lucigen Corp., Middleton, WI, USA) was used to fuse each solubility-tag to AaLINS in E. coli strain E. cloni ${ }^{\circledR}$ 10G, according to the manufacturer's protocol [39]. A DNA fragment of AaLINS was PCR-amplified from pAaLINS-ispA* using primers Lin-fw/Lin-rv and cloned into the linear pSol vectors [39]; the obtained plasmids are listed in Table 2 and Additional file 1: Table S2. A DNA fragment of AaLINS was PCR-amplified from pAaLINS-ispA* using primers P19/Lin-rv and then ligated to a vector fragment, which was PCR-amplified from pSol-BLAAaLINS using primers pSOL-fw/pSOLrv, to yield pSol-AaLINS. A DNA fragment of the gene of $6 \times$ His-BLA fused AaLINS was PCR-amplified from pSol-BLAAaLINS using primers His-fw/LIS-rv and then ligated to a vector fragment, which was PCR-amplified from pAaLINS-ispA* using primers P-fw/P-rv to yield pBLAAaLINS-ispA*. The sequence data for the genes of AaLINS and IspA*, which were optimized based on the codon-preference of Synechocystis, are available in GenBank (GenBank accession numbers: LX078595.1 and LX078599.1).

\section{Construction of $\varphi 80$-integrative conditional replication, integration, and modular (CRIM) plasmid, pAH162-P ${ }_{t a c}-\varphi 10-m v k$}

The DNA fragment containing $m v k$ from $M$. paludicola was PCR-amplified from pAH162- $\mathrm{P}_{t a c}-m v k$ [23] using primers $\mathrm{P} 1 / \mathrm{P} 2$, and then cloned into a linearized vector that was PCR-amplified with primers $\mathrm{P} 3 / \mathrm{P} 4$ from $\mathrm{pIspSM}$ [23] to yield pSTV28- ${ }_{t a c}-\phi 10-m v k$. The DNA fragment containing the $\mathrm{P}_{t a c}-\phi 10-m v k$ region was PCR-amplified from pSTV28- $\mathrm{P}_{t a c}-\phi 10-m v k$ using primers $\mathrm{P} 5 / \mathrm{P} 6$, and

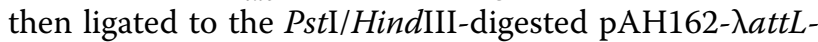
$\mathrm{Tc}^{\mathrm{R}}$ - $\lambda a t t R$ [51] and transformed into E. coli strain PIR2 (Thermo Fisher Scientific, Waltham, MA, USA).

\section{Construction of strains IP03 and IP04 using the Dual-In/ Out strategy}

Strains IP03 and IP04 were constructed from SWITCHPphoC $\Delta g c d$ [26] by the Dual-In/Out strategy [20, 51]. The $\phi 80 a t t L-\mathrm{Km}^{\mathrm{R}}-\phi 80 a t t R$ DNA fragment flanked with 50-bp homologous to the L-ldh (locus tag PAJ_p0276) and the adhE (locus tag PAJ_1411) site was PCR-amplified from pMWattphi [51] using primers Ldh-F/Ldh-R and adhE-F/adhE- $R$, respectively. To create a $\phi 80$ attB site in $\mathrm{SC17}(0)$, the PCR product was transformed by $\lambda$ Red-dependent homologous recombination [19]. After the removal of helper plasmid and $\mathrm{Km}^{\mathrm{R}}$-marker gene [20], SC17(0) $\Delta L$-ldh::\$80attB and $\mathrm{SC17}(0)$ $\triangle a d h E:: \phi 80 a t t B$ were generated, respectively. To obtain strains $\mathrm{SC17(0)} \quad \Delta L$-ldh::pAH162-P phoc $^{-m v a E S}$ and $\mathrm{SC17}(0) \Delta a d h E:: \mathrm{pAH} 162-\mathrm{P}_{t a c}-\phi 10-m v k$, the CRIM plasmid pAH162-P ${ }_{p h o c}-m v a E S$ was integrated into SC17(0) $\Delta L$-ldh::\$80attB, and pAH162- $\mathrm{P}_{t a c}-\phi 10-m v k$ was integrated into $\mathrm{SC} 17(0) \Delta a d h E:: \phi 80 a t t B$ by $\phi 80$-dependent recombination with pAH123-cat [20]. The genomic DNA of $\mathrm{SC} 17(0) \Delta L-l d h:: \mathrm{pAH} 162-\mathrm{P}_{p h o}-m v a E S$ was purified, fragmented, and then electroporated into SWITCHPphoC $\Delta g c d$ to transfer the chromosomal modification 
( $\Delta L$-ldh::pAH162- $\mathrm{P}_{\text {phoc }}-$ mvaES $\left[\mathrm{Tet}^{\mathrm{R}}\right]$ ) as previously reported [19]. The marker- and plasmid-less strain, IP03, was obtained by $\lambda$ integrase and excisionase-dependent marker excision with pMW-Int/Xis-cat [19]. Following the same procedure, strain IP04 (SWITCH-PphoC $\left.\Delta g c d \quad \Delta L-l d h:: \mathrm{P}_{p h o c}-m v a E S \quad \Delta a d h E:: \mathrm{P}_{t a c}-\phi 10-m v k\right)$ was generated from IP03 with the genomic DNA of SC17(0) $\Delta a d h E:: \mathrm{pAH} 162-\mathrm{P}_{t a c}-\phi 10-m v k$.

\section{Preparation of the bacterial lysate}

The $\mathrm{SC17}(0)$ strains harboring each pSol plasmid for expressing each AaLINS variant or AaLINS were grown on Luria-Bertani (LB)-agar for $16 \mathrm{~h}$ at $34{ }^{\circ} \mathrm{C}$. A single colony was inoculated into $3 \mathrm{~mL}$ of LB liquid medium containing $0.4 \mathrm{~g} / \mathrm{L}$ glucose and $4 \mathrm{~g} / \mathrm{L}$ of rhamnose. After cultivation at $30{ }^{\circ} \mathrm{C}$ for $21 \mathrm{~h}$ on a reciprocal shaker at $120 \mathrm{rpm}\left(\mathrm{OD}_{600}\right.$ was approximately 6$)$, the harvested cells were washed twice with extraction buffer $(50 \mathrm{mM}$ MOPS [pH 7.0], $10 \mathrm{mM} \mathrm{MgSO} \cdot 5 \mathrm{H}_{2} \mathrm{O}, 10 \%$ [v/v] glycerol, and $1 \mathrm{mM}$ dithiothreitol), and re-suspended in the same buffer. The cells were disrupted by sonication at $4{ }^{\circ} \mathrm{C}$ to obtain the crude homogenate including soluble and insoluble proteins. The crude homogenate was centrifuged $\left(21,600 \times g, 10 \mathrm{~min}, 4{ }^{\circ} \mathrm{C}\right)$ to obtain the supernatant or soluble protein fraction.

\section{SDS-PAGE analysis}

Protein concentration was quantified with a Pierce BCA protein assay kit (Thermo Fisher Scientific). The soluble protein fraction containing $10 \mu \mathrm{g}$ of protein was subjected to SDS-PAGE, and the crude homogenate was applied with the same volume $(\mu \mathrm{L})$ of the corresponding soluble protein fraction. The samples were reduced at $70{ }^{\circ} \mathrm{C}$ for 10 min with NuPAGE Sample Reducing Agent (Thermo Fisher Scientific). Proteins were separated on a NuPAGE 4-12\% Bis-Tris protein gel (Thermo Fisher Scientific) with MOPS SDS Running Buffer (Thermo Fisher Scientific) at $200 \mathrm{~V}$ for $90 \mathrm{~min}$, and then stained with InVision His-Tag In-Gel Stain (Thermo Fisher Scientific) to visualize the His-tagged fusion proteins with an antipolyhistidine label (nickel-nitrilotriacetic acid), according to the manufacturer's protocol. Fluorescence images were obtained at an excitation wavelength of $520 \mathrm{~nm}$. The gel was re-stained with CBB. An XL-Ladder Broad (intégrale Co., Ltd, Tokyo, Japan) was used as the molecular weight marker.

\section{Single-vial biotransformation assay}

The protein concentration of the soluble protein fraction was diluted to $300 \mathrm{mg} / \mathrm{L}$ in a final volume of $1 \mathrm{~mL}$ extraction buffer, which was previously supplemented with $15 \mu \mathrm{M}$ (final concentration) GPP lithium salt (SigmaAldrich, St. Louis, MO, USA), in a 22-mL Crimp Top vial
(PerkinElmer, Waltham, MA, USA). For the assay with the crude homogenate, the same volume $(\mu \mathrm{L})$ of the corresponding soluble protein fraction was applied in $1 \mathrm{~mL}$ extraction buffer with GPP. The vials were tightly capped with a $20 \mathrm{~mm}$ Crimp Top Aluminum Silver Cap with PTFE/Butyl Septa (PerkinElmer) and incubated at $30{ }^{\circ} \mathrm{C}$ for $26 \mathrm{~h}$ on a reciprocal shaker (120 rpm). Two hundred microliters of IPM were injected into the vial, which was thereafter vigorously shaken to extract $(S)$-linalool from the reaction buffer. The IPM layer was diluted by fivefold with ethanol, which was used to quantify $(S)$-linalool using a gas chromatography flame-ionization detector (GC-FID) as described below. Triplicate reactions were performed with bacterial lysates from three independent transformant colonies.

\section{(S)-linalool production in test tubes}

Cultivation was conducted essentially as previously reported [26]. The concentrations of glucose and $\mathrm{KH}_{2} \mathrm{PO}_{4}$ in the medium were set at 60 and $0.5 \mathrm{~g} / \mathrm{L}$, respectively. The test tubes were shaken at $30{ }^{\circ} \mathrm{C}$ for $48 \mathrm{~h}$ in a reciprocal shaker $(120 \mathrm{rpm})$. At least triplicate cultivations with independent transformant colonies were evaluated.

\section{Fed-batch fermentation in 1-L fermenter}

The cells were incubated at $34{ }^{\circ} \mathrm{C}$ for $16 \mathrm{~h}$ on an LB-agar plate including $\mathrm{Km}$ (dish diameter: $88 \mathrm{~mm}$ ). Whole cells on a plate were harvested with a $10-\mu \mathrm{L}$ inoculation loop and then transferred into $270 \mathrm{~mL}$ of medium $(44 \mathrm{~g} / \mathrm{L}$ glucose, $1.1 \mathrm{~g} / \mathrm{L} \mathrm{MgSO}_{4} \cdot 7 \mathrm{H}_{2} \mathrm{O}, 2.2 \mathrm{~g} / \mathrm{L}$ Bacto yeast extract [BD Biosciences, Franklin Lakes, NJ, USA], $1.8 \mathrm{~g} / \mathrm{L}$ $\mathrm{KH}_{2} \mathrm{PO}_{4}, 1.1 \mathrm{~g} / \mathrm{L}\left(\mathrm{NH}_{4}\right)_{2} \mathrm{SO}_{4}, 1.1 \mathrm{~g} / \mathrm{L}$ trisodium citrate, $11 \mathrm{mg} / \mathrm{L} \mathrm{MnSO}_{4} \cdot 5 \mathrm{H}_{2} \mathrm{O}, 11 \mathrm{mg} / \mathrm{L} \mathrm{FeSO}_{4} \cdot 7 \mathrm{H}_{2} \mathrm{O}, 0.11 \mathrm{~mL} / \mathrm{L}$ antifoam reagent GD-113 K [NOF Corporation, Tokyo, Japan] and $\mathrm{Km}$ ) overlaid with $30 \mathrm{~mL}$ of IPM in a 1-L fermenter. The glucose solution $(700 \mathrm{~g} / \mathrm{L})$ containing $0.7 \mathrm{~mL} / \mathrm{L}$ of GD-113 K was continuously fed from $9 \mathrm{~h}$ to the end of cultivation to maintain the glucose concentration at more than $5 \mathrm{~g} / \mathrm{L}$. The feeding rate was at approximately $1.5 \mathrm{~mL} / \mathrm{h}$ for IP04/pBLAAaLINS-ispA* and at approximately $2.0 \mathrm{~mL} / \mathrm{h}$ for SWITCH-PphoC $\Delta g c d /$ pAaLINS-ispA*. Fermentation was aerobically conducted with $300 \mathrm{~mL} / \mathrm{min}$ aeration; the culture temperature was set at $34{ }^{\circ} \mathrm{C}$ for $15 \mathrm{~h}$, and then shifted to $30{ }^{\circ} \mathrm{C}$ and kept at $30{ }^{\circ} \mathrm{C}$ until the end of cultivation; the culture $\mathrm{pH}$ was maintained at 6.8 with ammonia gas. The oxygen and $\mathrm{CO}_{2}$ concentrations in the exhausted-gas were measured every hour with an exhaust oxygen $\mathrm{CO}_{2}$ meter Model EX-1562-1 (Able \& Biott Co., Tokyo, Japan).

\section{Analysis of metabolites}

The $\mathrm{OD}_{600}$ was measured using a spectrometer (U-2900; Hitachi, Tokyo, Japan). The (S)-linalool concentration 
was quantified as follows. After vigorously vortexing the culture samples (mixture of cells, medium, and IPM), $100 \mu \mathrm{L}$ of the aliquot was added to $900 \mu \mathrm{L}$ of ethanol. These diluted samples were centrifuged $(21,600 \times g$, $5 \mathrm{~min}, 4^{\circ} \mathrm{C}$ ). The supernatants were used for $(S)$-linalool quantification with a GC-2025AF (Shimadzu, Kyoto, Japan) equipped with DB-5 capillary column (diameter, $0.25 \mathrm{~mm}$; length, $30 \mathrm{~m}$; thickness, $0.25 \mu \mathrm{m}$ ) (Agilent Technologies, Santa Clara, CA, USA) and FID as previously reported $[15,26]$. The concentration of $(S)$-linalool produced was quantified using a standard curve. (S)linalool concentration is represented, being assumed to completely exist in aqueous culture. After fractionizing the biphasic fermentation broth into a cell pellet, aqueous supernatant, and IPM fraction by centrifugation $\left(21,600 \times g, 10 \mathrm{~min}, 4{ }^{\circ} \mathrm{C}\right)$, glucose and MVA concentrations in the aqueous supernatant were quantified as previously reported [23]. The IPM fraction was used to identify the product, and the type of enantiomer was determined by GC-MS (Agilent 7890A GC and 5975C MSD, Agilent Technologies) equipped with a chiral GC capillary column Rt-bDEXsm (RESTEK Corporation, Bellefonte, PA, USA) (diameter, $0.25 \mathrm{~mm}$; length, $30 \mathrm{~m}$; thickness, $0.25 \mu \mathrm{m}$ ) using helium as the carrier gas. The injector temperature was maintained at $230{ }^{\circ} \mathrm{C}$. The GC oven temperature gradient was as follows: $115^{\circ} \mathrm{C}$ hold for $10 \mathrm{~min}$, increased to $225{ }^{\circ} \mathrm{C}\left(10{ }^{\circ} \mathrm{C} / \mathrm{min}\right)$, and held for $9 \mathrm{~min} .(R)$ - and $(S)$-linalool racemic reagent (Fujifilm Wako Pure Chemical, Osaka, Japan, catalog number: 126-00,993) and (R)-linalool reagent (Sigma-Aldrich, catalog number: 62139-25ML) were used to confirm the retention times of the $(R)$ - and $(S)$-enantiomers.

\section{Supplementary Information}

The online version contains supplementary material available at https://doi. org/10.1186/s12934-021-01543-0.

Additional file 1: Figure S1. Nucleotide sequences of AaLINS_pa and ispA*_pa. Figure S2. Construction of plasmids for over-expression of both AaLINS_pa and IspA*_pa. Figure S3. SDS-PAGE gel illustrating total, soluble, and insoluble expression of AaLINS and AaLINS_pa. Figure S4. Typical time-course profiles of fed-batch fermentation (1.6 g/L of $\left.\mathrm{KH}_{2} \mathrm{PO}_{4}\right)$ of SWITCH-PphoC $\triangle g c d / p A a L I N S-i s p A^{*}$ and IP04/pBLAAaLINS-ispA*. Figure S5. Growth inhibition of $P$. ananatis SC17 strain by exogenous linalool. Table S1. (S)-Linalool production in test-tube cultivation. Table S2. Bacterial strains and plasmids used for strain construction. Table S3. Primers used in this study.

\section{Abbreviations}

AaLINS: (S)-linalool synthase from Actinida arguta; AFV: AFV1-99 protein from Acidianus filamentous virus 1; BLA: Halophilic $\beta$-lactamase from Chromohalobacter sp. 560; CBB: Coomassie Brilliant Blue; Cm: Chloramphenicol; CoA: Coenzyme A; CRIM: Conditional replication, integration, and modular; DMAPP: Dimethylallyl pyrophosphate; EMP: Embden-Meyerhof-Parnas; ExCO $\mathrm{CO}_{2}$ Carbon dioxide in exhausted gas; FID: Flame-ionization detector; $6 \times$ His: Hexahistidine; GC: Gas chromatography; GPP: Geranyl pyrophosphate; Int: Integrase; IPM: Isopropyl myristate; IPP: Isopentenyl pyrophosphate; IspA*: S80F mutant of farnesyl pyrophosphate synthase from E. coli; Km: Kanamycin; LB: Luria-Bertani; MBP: Maltose binding protein; MOPS: 3-(N-morpholino)propanesulfonic acid; MS: Mass spectrometry; MVA: Mevalonate; OD: Optical density; PCR: Polymerase chain reaction; $P_{i}$ : Inorganic phosphate; SDS-PAGE: Sodium dodecyl sulfate-polyacrylamide gel electrophoresis; SlyD: FKBP-type peptidyl-prolyl cis-trans isomerase; SUMO: Small ubiquitin-like modifier; TCA: Tricarboxylic acid; Tet: Tetracycline; TPS: Terpene synthase; Tsf: E. coli Elongation factor; Xis: Excisionase.

\section{Acknowledgements}

We thank Dr. Joanna I Katashkina (Ajinomoto-Genetika Research Institute), Dr. Ekaterina Kazieva (Ajinomoto-Genetika Research Institute), and Dr. Keiichi Yokoyama (Ajinomoto Co., Inc.) for supporting this study.

\section{Authors' contributions}

NN drafted the manuscript and performed solubility tag screening, SDS-PAGE analysis, biotransformation assay, and fed-batch fermentation. YT and YN designed strains. YY constructed P. ananatis strains. YH designed plasmids for expressing (S)-linalool synthase and established the condition of test-tube cultivation. AM and MM constructed plasmids and conducted test-tube cultivation. YT, YN, and YU supervised the work and reviewed the final manuscript. All authors read and approved the final manuscript.

\section{Funding}

This research did not receive any specific grant from funding agencies in the public, commercial, or not-for-profit sectors.

\section{Availability of data and materials}

All data generated or analyzed during this study are included in this published article and its additional file.

\section{Ethics approval and consent to participate}

Not applicable.

\section{Consent for publication}

Not applicable.

\section{Competing interests}

The authors declare that they have no competing interests.

Received: 18 August 2020 Accepted: 18 February 2021

Published online: 02 March 2021

\section{References}

1. Lange BM, Rujan T, Martin W, Croteau R. Isoprenoid biosynthesis: the evolution of two ancient and distinct pathways across genomes. Proc Natl Acad Sci USA. 2000;97:13172-7

2. May PH, Barata LES. Rosewood exploitation in the Brazilian amazon: options for sustainable production. Econ Bot. 2004;58:257-65.

3. Cheng BH, Lin CY, Yeh TF, Cheng SS, Chang ST. Potential source of S-(+)linalool from Cinnamomum osmophloeum ct linalool leaf: Essential oil profile and enantiomeric purity. J Agric Food Chem. 2012;60:7623-8.

4. Schempp FM, Drummond L, Buchhaupt M, Schrader J. Microbial cell factories for the production of terpenoid flavor and fragrance compounds. J Agric Food Chem. 2018;66:2247-58.

5. Lukin I, Jach G, Wingartz I, Welters P, Schembecker G. Recovery of natural a-ionone from fermentation broth. J Agric Food Chem. 2019;67:13412-9.

6. Han GH, Kim SK, Yoon PKS, Kang Y, Kim BS, Fu Y, et al. Fermentative production and direct extraction of (-)-a-bisabolol in metabolically engineered Escherichia coli. Microb Cell Fact. 2016;15:185.

7. Shukal S, Chen X, Zhang C. Systematic engineering for high-yield production of viridiflorol and amorphadiene in auxotrophic Escherichia coli. Metab Eng. 2019;55:170-8.

8. Meadows AL, Hawkins KM, Tsegaye Y, Antipov E, Kim Y, Raetz L, et al. Rewriting yeast central carbon metabolism for industrial isoprenoid production. Nature. 2016:537:694-7.

9. Whited GM, Feher FJ, Benko DA, Cervin MA, Chotani GK, MCAuliffe JC, et al. Development of a gas-phase bioprocess for isoprene-monomer production using metabolic pathway engineering. Ind Biotechnol. 2010;6:152-63. 
10. Chen X, Zhang C, Lindley ND. Metabolic engineering strategies for sustainable terpenoid flavor and fragrance synthesis. J Agric Food Chem. 2019. https://doi.org/10.1021/acs.jafc.9b06203.

11. Aprotosoaie AC, Hăncianu M, Costache II, Miron A. Linalool: a review on a key odorant molecule with valuable biological properties. Flavour Fragr J. 2014;29:193-219.

12. Deng Y, Sun M, Xu S, Zhou J. Enhanced (S)-linalool production by fusion expression of farnesyl diphosphate synthase and linalool synthase in Saccharomyces cerevisiae. J Appl Microbiol. 2016;121:187-95.

13. Cao $X$, Wei $L$, Lin JY, Hua Q. Enhancing linalool production by engineering oleaginous yeast Yarrowia lipolytica. Bioresour Technol. 2017;245:1641-4.

14. Chen X, Yauk YK, Nieuwenhuizen NJ, Matich AJ, Wang MY, Perez RL, et al. Characterisation of an (S)-linalool synthase from kiwifruit (Actinidia arguta) that catalyses the first committed step in the production of floral lilac compounds. Funct Plant Biol. 2010;37:232-43.

15. Matsudaira A, Hoshino Y, Uesaka K, Takatani N, Omata T, Usuda Y. Production of glutamate and stereospecific flavors, (S)-linalool and (+)-valencene, by Synechocystis sp. PCC6803. J Biosci Bioeng. 2020;130:464-70.

16. Reiling KK, Yoshikuni Y, Martin VJJ, Newman J, Bohlmann J, Keasling JD. Mono and diterpene production in Escherichia coli. Biotechnol Bioeng. 2004;87:200-12.

17. Hofmeister DL, Thoden JB, Holden HM. Investigation of a sugar $\mathrm{N}$-formyltransferase from the plant pathogen Pantoea ananatis. Protein Sci. 2019:28:707-16.

18. Hara Y, Kadotani N, Izui H, Katashkina JI, Kuvaeva TM, Andreeva IG, et al. The complete genome sequence of Pantoea ananatis AJ13355, an organism with great biotechnological potential. Appl Microbiol Biotechnol. 2012;93:331-41.

19. Katashkina Jl, Hara Y, Golubeva LI, Andreeva IG, Kuvaeva TM, Mashko SV. Use of the $\lambda$ Red-recombineering method for genetic engineering of Pantoea ananatis. BMC Mol Biol. 2009;10:34. https://doi. org/10.1186/1471-2199-10-34.

20. Andreeva IG, Golubeva LI, Kuvaeva TM, Gak ER, Katashkina II, Mashko SV. Identification of Pantoea ananatis gene encoding membrane pyrroloquinoline quinone (PQQ)-dependent glucose dehydrogenase and pqqABCDEF operon essential for PQQ biosynthesis. FEMS Microbiol Lett. 2011;318:55-60.

21. Takumi K, Ziyatdinov MK, Samsonov V, Nonaka G. Fermentative production of cysteine by Pantoea ananatis. Appl Environ Microbiol. 2017;83:e02502-e2516. https://doi.org/10.1128/AEM.02502-16.

22. Hara Y, Fukui K, Yahagi D. Method for producing dicarboxylic acid. 2017; Patent US 20170298397 B2.

23. Nitta N, Tajima Y, Katashkina JI, Yamamoto Y, Onuki A, Rachi H, et al. Application of inorganic phosphate limitation to efficient isoprene production in Pantoea ananatis. J Appl Microbiol. 2020;128:763-74. https://doi. org/10.1111/jam.14521.

24. Nakano C, Kim HK, Ohnishi Y. Identification and characterization of the linalool/nerolidol synthase from Streptomyces clavuligerus. ChemBioChem. 2011;12:2403-7.

25. Brennan TCR, Turner CD, Krömer JO, Nielsen LK. Alleviating monoterpene toxicity using a two-phase extractive fermentation for the bioproduction of jet fuel mixtures in Saccharomyces cerevisiae. Biotechnol Bioeng. 2012;109:2513-22

26. Hoshino Y, Moriya M, Matsudaira A, Katashkina Jl, Nitta N, Nishio Y, et al. Stereospecific linalool production utilizing two-phase cultivation system in Pantoea ananatis. J Biotechnol. 2020;323:21-7.

27. Tokunaga H, Saito S, Sakai K, Yamaguchi R, Katsuyama I, Arakawa T, et al. Halophilic $\beta$-lactamase as a new solubility- and folding-enhancing tag protein: production of native human interleukin $1 a$ and human neutrophil a-defensin. Appl Microbiol Biotechnol. 2010;86:649-58.

28. Burg JM, Cooper CB, Ye Z, Reed BR, Moreb EA, Lynch MD. Large-scale bioprocess competitiveness: the potential of dynamic metabolic control in two-stage fermentations. Curr Opin Chem Eng. 2016;14:121-36.

29. Zhang Y, Wang J, Cao X, Liu W, Yu H, Ye L. High-level production of linalool by engineered Saccharomyces cerevisiae harboring dual mevalonate pathways in mitochondria and cytoplasm. Enzyme Microb Technol. 2020;134:109462.

30. Denby CM, Li RA, Vu VT, Costello Z, Lin W, Chan $\sqcup G$, et al. Industrial brewing yeast engineered for the production of primary flavor determinants in hopped beer. Nat Commun. 2018;9:1-10.

31. Mendez-perez D, Alonso-gutierrez J, Hu Q, Molinas M, Baidoo EEK, Wang $G$, et al. Production of jet fuel precursor monoterpenoids from engineered Escherichia coli. Biotechnol Bioeng. 2017;114:1703-12.
32. Katashkina Jl, Kazieva ED, Tajima Y, Mashko SV. Increased isoprene production by the recombinant Pantoea ananatis strain due to the balanced amplification of mevalonate pathway genes. Appl Biochem Microbiol. 2019;55:850-60

33. Martin VJJ, Pitera DJ, Withers ST, Newman JD, Keasling JD. Engineering a mevalonate pathway in Escherichia coli for production of terpenoids. Nat Biotechnol. 2003:21:796-802

34. Withers ST, Gottlieb SS, Lieu B, Newman JD, Keasling JD. Identification of isopentenol biosynthetic genes from Bacillus subtilis by a screening method based on isoprenoid precursor toxicity. Appl Environ Microbiol. 2007;73:6277-83

35. Yoshikuni Y, Dietrich JA, Nowroozi FF, Babbitt PC, Keasling JD. Redesigning enzymes based on adaptive evolution for optimal function in synthetic metabolic pathways. Chem Biol. 2008;15:607-18.

36. Tashiro M, Kiyota H, Kawai-Noma S, Saito K, Ikeuchi M, lijima Y, et al. Bacterial production of pinene by a laboratory-evolved pinene-synthase. ACS Synth Biol. 2016;5:1011-20

37. Hartwig S, Frister T, Alemdar S, Li Z, Scheper T, Beutel S. SUMO-fusion, purification, and characterization of a (+)-zizaene synthase from Chrysopogon zizanioides. Biochem Biophys Res Commun. 2015;458:883-9.

38. Sonke T, De Jong RM. Valencene synthase. 2012; Patent US 20190136221 A1.

39. Steinmetz E, Auldridge M. Screening fusion tags for improved recombinant protein expression in E. coli with the Expresso ${ }^{\circledR}$ solubility and expression screening system. Curr Protoc Protein Sci. 2017;90:5271-52720.

40. Heeres AS, Picone CSF, van der Wielen LAM, Cunha RL, Cuellar MC. Microbial advanced biofuels production: overcoming emulsification challenges for large-scale operation. Trends Biotechnol. 2014;32:221-9.

41. Xiaowu L, Yun H, Zhuying W, Chunjiao W, Zhibing L, Tianhui X, et al. Method of sequence optimization for improved recombinant protein expression using a particle swarm optimization Algorithm. 2011; Patent US20110081708 A1.

42. Jin P, Kang Z, Zhang N, Du G, Chen J. High-yield novel leech hyaluronidase to expedite the preparation of specific hyaluronan oligomers. Sci Rep. 2014;4:4471.

43. Korman TP, Opgenorth PH, Bowie JU. A synthetic biochemistry platform for cell free production of monoterpenes from glucose. Nat Commun. 2017:8:15526.

44. Venayak N, Anesiadis N, Cluett WR, Mahadevan R. Engineering metabolism through dynamic control. Curr Opin Biotechnol. 2015;34:142-52.

45. Dauner M, Storni T, Sauer U. Bacillus subtilis metabolism and energetics in carbon-limited and excess-carbon chemostat culture. J Bacteriol. 2001;183:7308-17.

46. Kalily E, Hollander A, Korin B, Cymerman I, Yaron S. Mechanisms of resistance to linalool in Salmonella Senftenberg and their role in survival on basil. Environ Microbiol. 2016;18:3673-88.

47. Shah AA, Wang C, Chung YR, Kim JY, Choi ES, Kim SW. Enhancement of geraniol resistance of Escherichia coli by MarA overexpression. J Biosci Bioeng. 2013;115:253-8.

48. Terpe K. Overview of bacterial expression systems for heterologous protein production: From molecular and biochemical fundamentals to commercial systems. Appl Microbiol Biotechnol. 2006;72:211-22.

49. Lin YL, Lee YR, Huang WK, Chang ST, Chu FH. Characterization of S-(+)linalool synthase from several provenances of Cinnamomum osmophloeum. Tree Genet Genomes. 2014;10:75-86.

50. Nieuwenhuizen NJ, Green SA, Chen X, Bailleul EJD, Matich AJ, Wang MY, Atkinson RG. Functional genomics reveals that a compact terpene synthase gene family can account for terpene volatile production in Apple. Plant Physiol. 2013;161:787-804.

51. Minaeva NI, Gak ER, Zimenkov DV, Skorokhodova AY, Biryukova IV, Mashko SV. Dual-In/Out strategy for genes integration into bacterial chromosome: a novel approach to step-by-step construction of plasmid-less markerless recombinant $E$. coli strains with predesigned genome structure. BMC Biotechnol. 2008;8:1-11.

\section{Publisher's Note}

Springer Nature remains neutral with regard to jurisdictional claims in published maps and institutional affiliations. 